\title{
Generation and characterization of high affinity human monoclonal antibodies that neutralize staphylococcal enterotoxin B
}

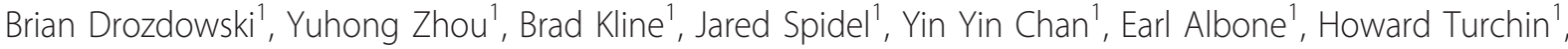 \\ Qimin Chao', Marianne Henry', Jacqueline Balogach', Eric Routhier', Sina Bavari², Nicholas C Nicolaides', \\ Philip M Sass', Luigi Grasso ${ }^{1 *}$
}

\begin{abstract}
Background: Staphylococcal enterotoxins are considered potential biowarfare agents that can be spread through ingestion or inhalation. Staphylococcal enterotoxin B (SEB) is a widely studied superantigen that can directly stimulate T-cells to release a massive amount of proinflammatory cytokines by bridging the MHC II molecules on an antigen presenting cell (APC) and the V $\beta$ chains of the T-cell receptor (TCR). This potentially can lead to toxic, debilitating and lethal effects. Currently, there are no preventative measures for SEB exposure, only supportive therapies.
\end{abstract}

Methods: To develop a potential therapeutic candidate to combat SEB exposure, we have generated three human B-cell hybridomas that produce human monoclonal antibodies (HuMAbs) to SEB. These HuMAbs were screened for specificity, affinity and the ability to block SEB activity in vitro as well as its lethal effect in vivo.

Results: The high-affinity HuMAbs, as determined by BiaCore analysis, were specific to SEB with minimal crossreactivity to related toxins by ELISA. In an immunoblotting experiment, our HuMAbs bound SEB mixed in a cell lysate and did not bind any of the lysate proteins. In an in vitro cell-based assay, these HuMAbs could inhibit SEB-induced secretion of the proinflammatory cytokines (INF- $\gamma$ and TNF- $\alpha$ ) by primary human lymphocytes with high potency. In an in vivo LPS-potentiated mouse model, our lead antibody, HuMAb-154, was capable of neutralizing up to $100 \mu \mathrm{g}$ of SEB challenge equivalent to 500 times over the reported $\mathrm{LD}_{50}(0.2 \mu \mathrm{g})$, protecting mice from death. Extended survival was also observed when HuMAb-154 was administered after SEB challenge.

Conclusion: We have generated high-affinity SEB-specific antibodies capable of neutralizing SEB in vitro as well as in vivo in a mouse model. Taken together, these results suggest that our antibodies hold the potential as passive immunotherapies for both prophylactic and therapeutic countermeasures of SEB exposure.

\section{Introduction}

Staphylococcus aureus is a Gram-positive bacterium responsible for skin, soft-tissue, respiratory, bone, joint, and endovascular disorders, and has potentially lethal effects due to endocarditis, sepsis, and toxic shock syndrome [1]. Virulence for a number of the pathogenic manifestations of $S$. aureus is caused by a handful of toxins produced and secreted by the bacterium, which include among others the toxins responsible for toxic

\footnotetext{
* Correspondence: grasso@morphotek.com

${ }^{1}$ Morphotek Inc., 210 Welsh Pool Road, Exton, PA, USA

Full list of author information is available at the end of the article
}

shock syndrome, TSST-1, and S. aureus enterotoxins (SEs), which cause food poisoning. About twenty enterotoxins have been described that exhibit and are defined by their emetic activity in primates [2-6]. Enterotoxins are also referred to as superantigens (SAgs) because they bypass antigen processing by forming a bridge between the MHC II molecules on an antigen presenting cell (APC) and the V $\beta$ chain of the T-cell receptor (TCR) causing a massive release of cytokines, such as interferon-gamma (INF- $\gamma$ ) and tumor necrosis factoralpha (TNF- $\alpha$ ). SEB is one of the most studied enterotoxins notoriously associated with food poisoning

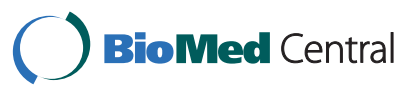


through ingestion. Symptoms include a rapid onset of fever, intense nausea, vomiting, cramping abdominal pain, and diarrhea. Most cases are self-limited and resolve in 8-24 hours. If aerosolized, SEB could cause severe cases of pulmonary edema and respiratory failure $[7,8]$. Since it has the potential to be weaponized and used as an incapacitating or lethal agent, the National Institute of Allergy and Infectious Diseases (NIAID) and the Centers for Disease Control and Prevention (CDC) recognize $\mathrm{SEB}$ as a category $\mathrm{B}$ agent.

Currently, there are no commercial preventative measures or therapies for SEB exposure based on passive (antibodies) or active (vaccines) immunotherapy, despite the fact that multiple attempts to develop therapies have met with various degrees of success. SEB mutants generated by site-directed mutagenesis and lacking superantigenic effects are highly immunogenic in mice and rhesus monkeys, demonstrating their potential as a vaccine for prophylactic intervention [9]. Woody et al have studied the vaccine potential of mutant staphylococcal SEB proteins and showed that some were able to elicit a protective antibody response in LPS-potentiated mice [10]. Strategies aimed at disrupting SEs interaction with the immune system include low-molecular antagonist peptides, based on the SEs conserved regions, as well as soluble T-cell receptor that can sequester SEB [11-14]. The use of mouse monoclonal anti-SEB antibodies to study important epitope determinants essential for $\mathrm{MHC} / \mathrm{TCR}$ binding has led others to explore the use of anti-SEB antibodies for blocking SEB from engaging the immune system [15]. Other notable studies have included a murine toxic shock syndrome toxin 1 (TSST-1)-specific monoclonal antibody (MAb) which crossreacted to SEB by ELISA and partially inhibited SEB-induced T-cell mitogenesis as well as TNF $\alpha$ secretion in human PBMCs in a dose-dependent manner in vitro [16]. Also, LeClaire et al demonstrated the feasibility of using a passive immunity strategy utilizing SEBspecific MAbs raised in chicken to block SEB-mediated toxicity in Rhesus monkeys [17]. In this study, animals $(4 / 4)$ that received molar ratios of antibody to toxin of 21:1 and 37:1 survived an aerosolized exposure of approximately $5 \mathrm{LD}_{50}$ of SEB.

Pooled human sera with titers against SEs and TSST-1 were reported to suppress in vitro SEB-induced human $\mathrm{T}$-cell proliferation while affinity purified anti-SEB antibodies from the pooled human sera prophylactically protected mice from a SEB lethal challenge [18]. More recently, chimeric mouse-human antibodies with high affinities for SEB were reported to inhibit SEB induced proliferation and cytokine production in both human PBMCs and mouse splenocytes in vitro [19]. In this report, we detail the generation and selection of fully human monoclonal antibodies (HuMAbs) specific for
SEB derived from human B-cell hybridomas. These antibodies showed biological activity towards SEB in vitro. In addition, HuMAb-154, which displayed the highest anti-SEB affinity, exhibited prophylactic as well as therapeutic activity in a mouse model of SEB-induced lethality.

\section{Materials and methods \\ Generation of HuMAbs}

Human B-cell hybridomas producing SEB-specific HuMAbs were generated using Human MORPHO$\mathrm{DOMA}^{\oplus}$ technology as previously described [20]. Briefly, leukopacks were obtained from healthy individuals with anti-SEB serum antibody titers. B cells were isolated from the PBMC population using an EasySep human B cell enrichment kit (StemCell Technologies). B cells were cultured for 7 days in IMDM media (Invitrogen) supplemented with $10 \%$ heat-inactivated FBS (JRH BioSciences), $10 \mathrm{ng} / \mathrm{ml}$ human IL-2, $10 \mathrm{ng} / \mathrm{ml}$ human IL-10 (PeproTech), $2 \mathrm{mM}$ L-glutamine, $0.1 \mathrm{mM}$ nonessential amino acids, $1 \mathrm{mM}$ sodium pyruvate, $55 \mu \mathrm{M}$ 2-mercaptoethanol (Invitrogen) in the presence of irradiated $\mathrm{CHO}$ feeder cells. Cultured B cells were then electrofused with CB-F7 heteromyeloma cells [21] (kind gift from Dr. Roland Grunow, Robert Koch-Institute) using the Cyto Pulse CEEF-50 apparatus (Cyto Pulse Sciences) to generate hybridomas. Individual hybridoma clones were screened by SEB-specific ELISA (Recombinant SEB, highly purified, from Toxin Technology, Inc.) for specific SEB-reactive antibodies. Clones highly reactive with SEB without crossreactivity to the other unrelated antigens were subcloned followed by ELISA screening to confirm retention of SEB specificity. Light and heavy chain genes of lead clones were sequenced and cloned for recombinant expression of corresponding antibodies in $\mathrm{CHO}$ cells.

\section{HuMAb ELISA reactivity to related toxins}

Related Staphylococcus enterotoxins (SEs), SEB, SEA, SED, SEC1, TSST-1 (Toxin Technology, Inc.), and tetanus toxoid (Cylex Inc.) were diluted to $0.5 \mu \mathrm{g} / \mathrm{ml}$ in coating buffer (50 mM carbonate-bicarbonate, $\mathrm{pH} 9.4$ ) and coated in microtiter plates overnight at $4^{\circ} \mathrm{C}$. Plates were blocked and ELISA-based screening was performed as for identification of HuMAbs.

\section{SDS-PAGE and Western blotting}

SEB at $500 \mathrm{ng}$ and $20 \mu \mathrm{g}$ of 293 cell lysates were diluted in SDS sample buffer then subjected to reducing and non-reducing SDS-PAGE on a 4 to $12 \%$ gradient gel in MES buffer (NOVEX, San Diego, CA). Electrophoresed proteins were transferred onto nitrocellulose sheets. After transfer, the sheets were blocked with TBS containing 5\% milk and $0.1 \%$ Tween-20 (5\% milk/TBS-T) 
for 1 hour at room temperature with gentle agitation. Blots were agitated for 1 hour with HuMAbs at $1 \mu \mathrm{g} / \mathrm{ml}$ diluted in $5 \%$ milk/TBS-T. The blots were then washed four times (for $5 \mathrm{~min}$ each time with agitation) with TBS containing $0.1 \%$ Tween-20 (TBS-T), followed by gentle agitation for 1 hour at room temperature with peroxidase-conjugated goat anti-human $\operatorname{IgG}+\mathrm{M}(\mathrm{H}+\mathrm{L})$ $\mathrm{Ab}$ (Jackson Immuno Laboratories) (diluted 1:10,000 in $5 \%$ milk/TBS-T). The blots were washed again four times and the immunoreactive proteins were visualized using SuperSignal West Femto Luminescent Substrate (Pierce).

\section{Surface plasmon resonance}

SEB was diluted in $10 \mathrm{mM}$ sodium acetate $\mathrm{pH} 5.5$, to a final concentration of $10 \mu \mathrm{g} / \mathrm{ml}$ and coupled to the surface of a research-grade CM5 chip (Biacore, Inc., Piscataway, NJ) by standard amine chemistry (NHS-EDC, Biacore, Inc.), to a level of 50-250 RU of SEB bound. The remaining active sites were quenched using $1 \mathrm{M}$ ethanolamine. A reference flow cell consisting of an activated and quenched surface in the absence of antigen was created and used to normalize readings from injections of anti-SEB-containing samples. Purified HuMAbs were diluted into HBS-EP buffer (Biacore, Inc.) to final concentrations of $50 \mathrm{nM}, 25 \mathrm{nM}, 12.5 \mathrm{nM}$, $6.25 \mathrm{nM}, 3.13 \mathrm{nM}, 1.56 \mathrm{nM}$ and $0.78 \mathrm{nM}$. The running buffer used was HBS-EP with a flow rate of $30 \mu \mathrm{l} / \mathrm{min}$. Regeneration of the surface was performed by two injections of $10 \mathrm{mM} \mathrm{HCl}$ for 30 seconds at a flow rate of $100 \mu \mathrm{l} / \mathrm{min}$. The on- (ka) and off-rate (kd) of HuMAbs were determined by observing the signal over time for triplicate injections at each concentration above. Blank injections of HBS-EP were also performed to assess noise, and to normalize injection data. All samples were randomly injected for two minutes using the KINJECT command and the dissociation phase of binding was observed for 10 minutes. The data were fitted to a bivalent analyte binding model, using BiaEvaluation 4.1 software (Biacore, Inc.), as no mass transfer effects were obvious in control experiments. A steady-state binding constant $\left(\mathrm{K}_{\mathrm{D} 1}\right)$ was derived from the observed on- and off-rates ( $\mathrm{k}_{\mathrm{a} 1}$ and $\mathrm{k}_{\mathrm{d} 1}$, respectively) for first-site binding of antibody to SEB.

\section{In vitro toxin neutralization}

Human peripheral blood mononuclear cells (PBMCs) were used to determine the ability of HuMAbs to inhibit SEB-induced T-cell cytokine production and measure their in vitro $\mathrm{EC}_{50}$. PBMCs isolated from blood drawn from healthy volunteers were purified by Ficoll-Paque Plus (Amersham-Pharmacia). Approximately $1 \times 10^{5}$ cells in $100 \mu \mathrm{l}$ of IMDM medium supplemented with 10\% heat-inactivated FBS (JRH Biosciences), $2 \mathrm{mM}$
L-glutamine, $0.1 \mathrm{mM}$ nonessential amino acids , $1 \mathrm{mM}$ sodium pyruvate , $55 \mu \mathrm{M}$ 2-mercaptoethanol (Invitrogen), $5 \mu \mathrm{g} / \mathrm{ml}$ gentamicin (Gibco), were cultured in 96well flat-bottom tissue culture plates and incubated at $37^{\circ} \mathrm{C}$ in $5 \% \mathrm{CO} 2$. Various $4 \mathrm{x}$ concentrations of HuMAbs or combination thereof at different ratios were incubated with SEB ( $4 \mathrm{x}$ its in vitro $\mathrm{ED}_{50}$, data not shown) for $1 \mathrm{~h}$ and the mixture subsequently added to the PBMCs (1x final concentration for both HuMAbs and SEB). After 18-22 hours, supernatants were transferred to IFN- $\gamma$ - and TNF- $\alpha$-coated ELISA plates $(75 \mu \mathrm{l} /$ well $)$ and assayed using an ELISA kit (R\&D System) following the manufacturer's recommended procedure. $\mathrm{EC}_{50} \mathrm{cal}-$ culations of HuMAbs were performed using Prism4 (GraphPad Software). The sensitivity limit of the IFN- $\gamma$ and TNF- $\alpha$ ELISA is $16 \mathrm{pg} / \mathrm{ml}$.

\section{In vivo toxin neutralization}

In vivo studies were conducted by TransPharm Preclinical Solutions as well as at US Army Medical Research Institute for Infectious Diseases. Female Balb/C mice ordered from Charles River weighing 14-16 g were acclimated to housing conditions and handled in accordance with AUP number TP-06-08. They were 7-8 weeks old on Day 1 of the experiment. The animals were fed irradiated Rodent Diet 5053 (LabDiet $^{\mathrm{TM}}$ ) and water ad libitum. Mice were housed in static cages with Bed$\mathrm{O}^{\prime} \mathrm{Cobs}^{\mathrm{TM}}$ bedding inside BioBubble ${ }^{\odot}$ Clean Rooms that provide H.E.P.A filtered air into the bubble environment at 100 complete air changes per hour. All challenges were carried out in the BioBubble environment. The environment was controlled to a temperature range of $71^{\circ} \pm 4^{\circ} \mathrm{F}$ and a humidity range of $30-70 \%$. All animals were observed for clinical signs at least once daily. All procedures carried out in this experiment were conducted in compliance with all the laws, regulations and guidelines of the National Institutes of Health (NIH) and with the approval of the TPPS Animal Care and Use Committee.

Mice were challenged with various concentrations of SEB (Toxin Technology, FL) to assess the protective activity of HuMAb-154 in vivo. The presumptive $\mathrm{LD}_{50}$ of SEB in Balb/C mice was $0.2 \mu \mathrm{g} /$ mouse [18]. SEB challenges of $1,5,10,20,50$, and $100 \mu \mathrm{g} \mathrm{SEB} /$ mouse were premixed with $500 \mu \mathrm{g}$ of HuMAb-154 then injected intraperitoneally. To spare additional animals from an unnecessary sacrifice, only mice treated with HuMAb154 were challenged with SEB doses higher than 5 ug of SEB. SEB toxicity was potentiated by the administration of LPS $(150 \mu \mathrm{g} /$ mouse) three hours following the SEB challenge. Challenge controls were injected with SEB alone and LPS alone. Survival was determined after 3 days. Time course studies were conducted to assess the therapeutic activity of a $500 \mu \mathrm{g}$ dose of HuMAb-154 
administered at $0,0.5$ and $1 \mathrm{hr}$ following a challenge of $5 \mu \mathrm{g}$ and $10 \mu \mathrm{g}$ of SEB. An LPS potentiating dose of $150 \mu \mathrm{g} /$ mouse was delivered three hours following the SEB challenge. Survival was determined after 4 days.

\section{Statistical methods}

Data was analyzed in the Prism software package (GraphPad Software, Inc). An unpaired two-tailed t-test was used to analyze in vitro neutralization assays while in vivo survival curves were analyzed using the Log-rank (Mantel Cox) test.

\section{Results}

\section{Generation of human monoclonal antibodies} targeting SEB

Healthy volunteers whose sera showed pre-existing high immune reactivity to SEB were identified by ELISA. B-cells isolated from these selected donors' blood samples were cultured and expanded using an in vitro culture system. Expanded B-cells were subsequently fused to myeloma cells to generate a library of hybridomas. We screened the conditioned media produced by these hybridomas by ELISA for reactivity to STEB, an SEB vaccine which is a recombinant and attenuated form of SEB [9]. STEB contains site mutations in the hydrophobic binding loop, polar binding pocket, and disulfide loop (L45R, Y89A, and Y94A, respectively) yet retains its antigenic characteristics [22]. STEB reactive hybridoma clones were further screened against SEB as well as a panel of nonrelated antigens to confirm reactivity and determine specificity. We then subcloned and rescreened SEB-specific hybridomas by ELISA. Three hybridomas, HuMAb-79G9, HuMAb-100C9 and HuMAb-154, met the binding (Figure 1) and selectivity

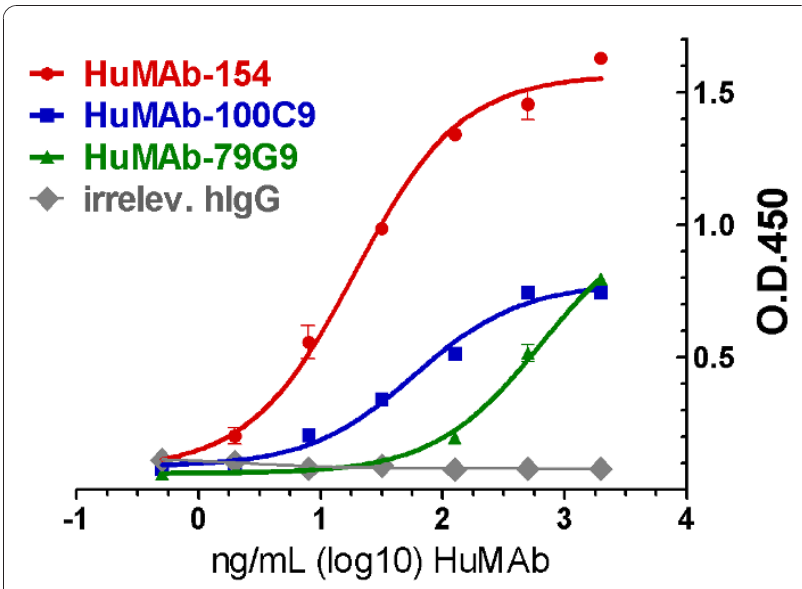

Figure 1 Binding strength of HuMAbs was tested by ELISA using microplates coated with SEB. Each point represents the average of triplicate samples \pm the SD and the data shown are representative of two or more independent experiments. criteria (data not shown) and were chosen for further analyses. We determined the heavy and light chain encoding sequences of these three human IgG1 kappa antibodies and constructed DNA expression vectors that allowed us to recombinantly expressed HuMAbs in mammalian cells for large-scale production.

\section{Specificity and binding potency of anti-SEB HuMAbs}

Western blotting was used to address whether the HuMAbs reacted non-specifically to cellular proteins. Human cell lysates were spiked with SEB, loaded on SDS-page under reducing and non-reducing conditions, and then probed with each HuMAb. All three HuMAbs recognized the $28 \mathrm{kD} \mathrm{SEB}$ in the cell lysate without binding any other cellular protein (Figure 2) demonstrating the specificity of these HuMAbs.

In addition, we carried out surface plasmon resonance (SPR) analyses to determine the binding kinetics of each HuMAb. SEB was immobilized on a CM5 chip followed by injections at various concentrations of HuMAb. Using a bivalent binding model, we determined steadystate binding $\left(\mathrm{K}_{\mathrm{D} 1}\right)$ constants. HuMAb-154 displayed the strongest affinity $\left(K_{\mathrm{D} 1}\right.$ of $\left.290 \mathrm{pM}\right)$ (Table 1$)$. The different binding strengths measured by SPR correlated well with the binding values as determined by antigenspecific ELISA (Figure 1). Additional SPR analysis using

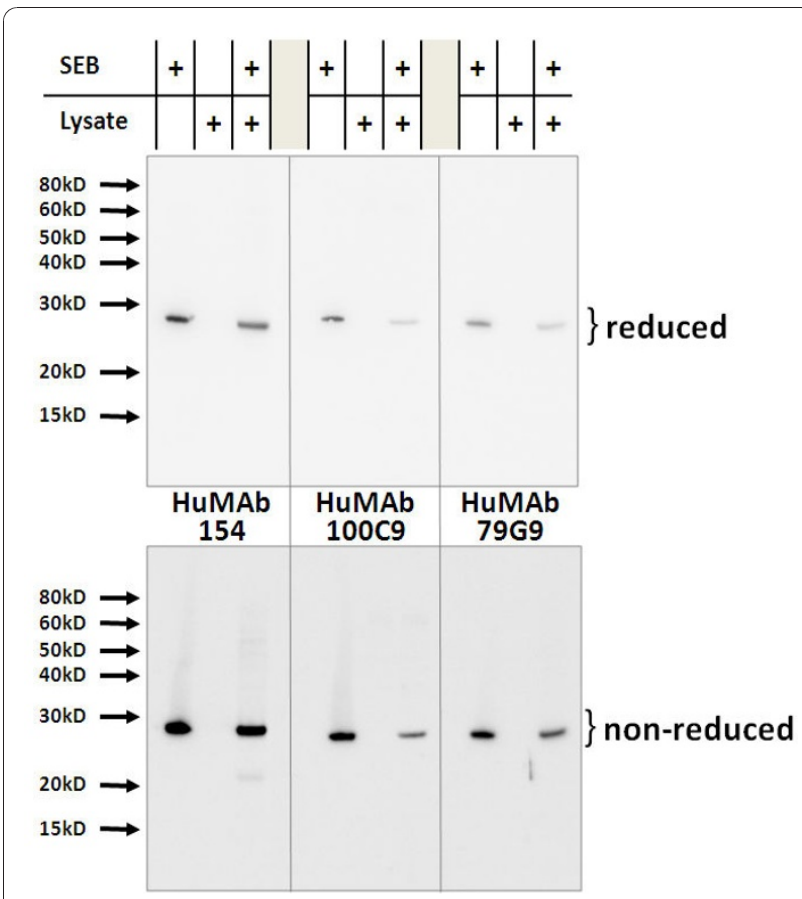

Figure 2 HuMAb specificity demonstrated by Western blotting Human cell lysates $(20 \mu \mathrm{g})$ spiked with SEB $(0.5 \mu \mathrm{g})$ were blotted under reducing and non-reducing conditions then probed with HuMAbs. HuMAbs bind only SEB within cell lysates without binding any of the lysate proteins. 
Table 1 Binding kinetics of HuMAbs as determined by surface plasmon resonance

\begin{tabular}{cccc}
\hline HuMAb & $\mathbf{k}_{\mathrm{a} \mathbf{1}}$ & $\mathbf{k}_{\mathbf{d} \mathbf{1}}$ & $\mathbf{K}_{\mathrm{D} \mathbf{1}}(\mathbf{n M})$ \\
\hline $\mathbf{7 9 G 9}$ & $9.56 \mathrm{E}+03$ & $2.39 \mathrm{E}-04$ & 25.0 \\
$\mathbf{1 0 0 C 9}$ & $207 \mathrm{E}+03$ & $11.3 \mathrm{E}-04$ & 5.46 \\
$\mathbf{1 5 4}$ & $93.2 \mathrm{E}+03$ & $0.27 \mathrm{E}-04$ & 0.29 \\
\hline
\end{tabular}

a competitive binding format revealed that HuMAb-154 and HuMAb-100C9 shared the epitope or at least have epitopes in close proximity to one another since HuMAb-100C9 cannot bind SEB that has been saturated with HuMAb-154 (data not shown).

HuMAbs neutralize SEB-induced cytokine production by human lymphocytes

To examine the biological activity of HuMAbs in vitro, a cell-based assay was employed that measures inhibitory effects on SEB-induced secretion of proinflammatory cytokines by human peripheral blood lymphocytes. Primary human T-cells stimulated with SEB in vitro will upregulate the secretion of cytokines including INF- $\gamma$ and TNF- $\alpha$, which in vivo mediate SEB toxicity. Secretion levels of these cytokines can be monitored using INF- $\gamma$ - and TNF- $\alpha$-specific ELISAs. An irrelevant human IgG1 $\kappa$ had no significant inhibitory activity on SEB-induced cytokine production whereas HuMAb79 G9 showed a dose-dependent inhibitory activity (Figure 3A). In subsequent experiments, it was observed that each HuMAb could block SEB-induced activation of human T-cells whereby HuMAb-154 showed the highest potency (Figure $3 \mathrm{~B}$ ), suggesting a correlation between high affinity and potency. It was also observed that HuMAbs alone were not cytotoxic to PBMCs or induced INF- $\gamma$ and TNF- $\alpha$ secretion as compared to the medium control (data not shown). To define accurately

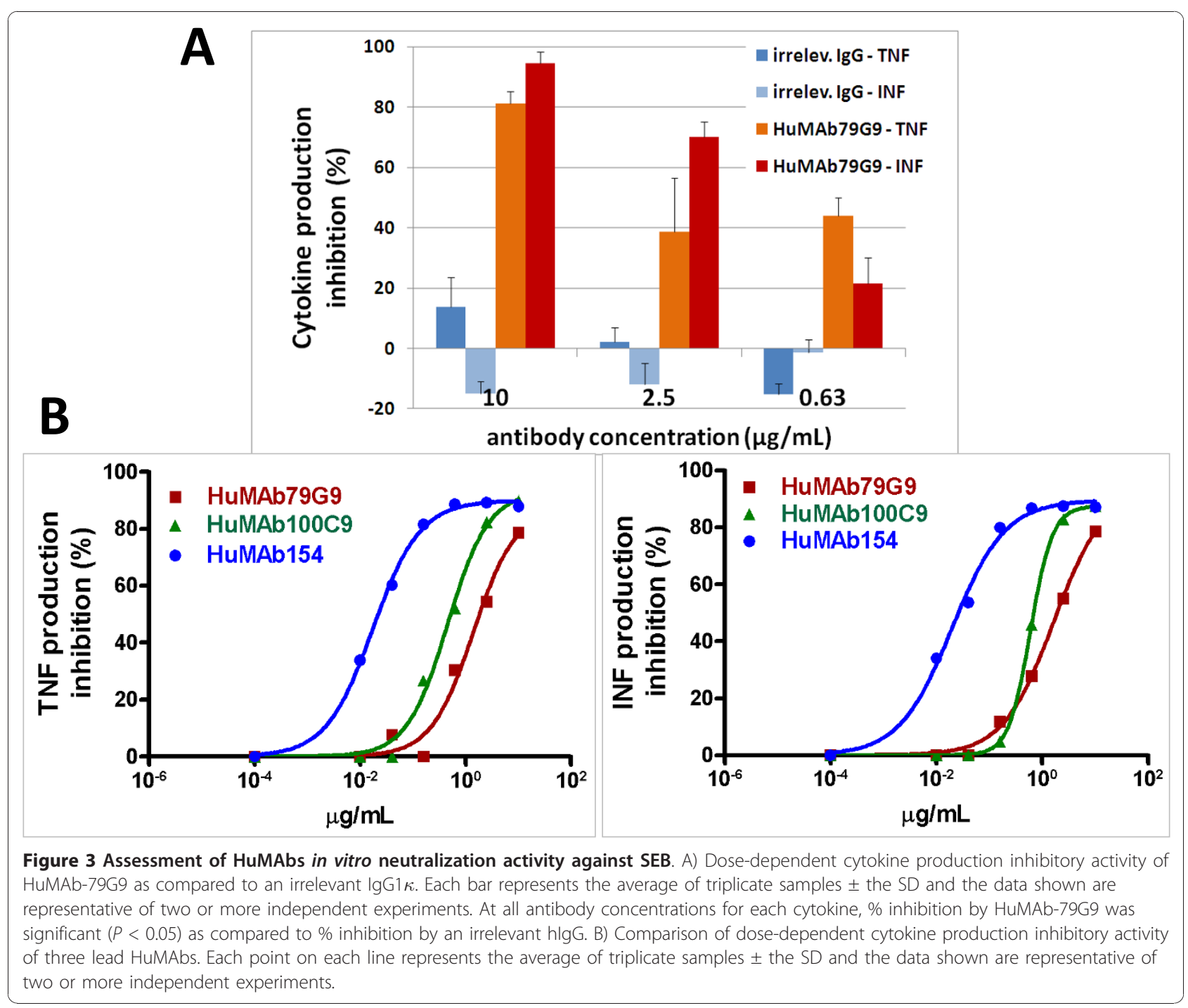


the $50 \%$ effective dose $\left(\mathrm{EC}_{50}\right)$ of HuMAb-154, several experiments were conducted using independent batches of purified HuMAb-154. Regardless of the batch used, operator, or the cytokine analyzed, the $\mathrm{EC}_{50}$ of HuMAb154 always remained below $1 \mathrm{ng} / \mathrm{mL}$ (Table 2).

\section{Crossreactivity of HuMAb-154 to other bacterial toxins}

To test whether HuMAb-154 crossreacted to other bacterial toxins, a panel comprising different staphylococcal toxins (SEA, SEB, SED, TSST-1, and SEC1) and the less related tetanus toxin (TT) were screened by ELISA. Toxins were readily detected by the corresponding toxin-specific control antibodies (Figure 4A), thus confirming that all toxins had been efficiently coated on the ELISA microplate. Under these conditions, HuMAb-154 showed the highest reactivity to SEB while having some cross-reactivity to other enterotoxins (SEA, SED, and SEC1, Figure 4B) but not to TSST-1 or TT toxins. An irrelevant human IgG1 did not react with any of the toxins (Figure 4B) confirming the specificity of our assay. HuMAb-154 reactivity to SEC1 is plausible being that SEB and SEC1 share a high degree of amino acid homology whereas SEA and SED show a lower degree of amino acid homology $[23,24]$. The reactivity of HuMab-154 to SEA and SED is unclear although crystal structure analyses have shown that SEs have similar protein folds despite very different amino acid sequences [25-27].

\section{Prophylactic administration of HuMAb-154 confers survival of mice exposed to lethal doses of SEB} Because HuMAb-154 exhibited the best affinity and potency in vitro, we focused on this HuMAb for in vivo efficacy testing. An LPS-potentiated mouse model $[18,28]$ reported an $\mathrm{LD}_{50}$ of $\sim 0.2 \mu \mathrm{g}$ of SEB. Using the same model, we observed that control groups with LPS alone and HuMAb-154 alone had no lethal or toxic effects on mice (Figure 5A). An LPS potentiating effect at five fold of the reported $\mathrm{LD}_{50}(1 \mu \mathrm{g}$ of SEB$)$ was observed which resulted in $20 \%$ mortality as compared to no mortality with $1 \mu \mathrm{g}$ of SEB alone (Figure $5 \mathrm{~A}$ ). A challenge of $5 \mu \mathrm{g}$ of SEB resulted in $100 \%$ mortality regardless of whether LPS was administered or not.

Table 2 HuMAb-154 lot comparison of inhibitory activity measured by $\mathrm{EC}_{50}$

\begin{tabular}{cccc}
\hline Operator & HuMAb-154 & ${ }^{\mathrm{a}} \mathrm{TNF} \boldsymbol{\alpha} \mathrm{EC}_{\mathbf{5 0}}$ & ${\text { INF } \boldsymbol{\gamma} \text { EC }_{\mathbf{5 0}}}$ \\
\hline 1 & Lot \#1 & 0.54 & 0.44 \\
2 & Lot \#2 & 0.52 & 0.49 \\
1 & Lot \#1 & 0.56 & 0.48 \\
2 & Lot \#2 & 0.52 & 0.50 \\
1 & Lot \#1 & 0.52 & 0.51 \\
2 & Lot \#2 & 0.64 & 0.50
\end{tabular}

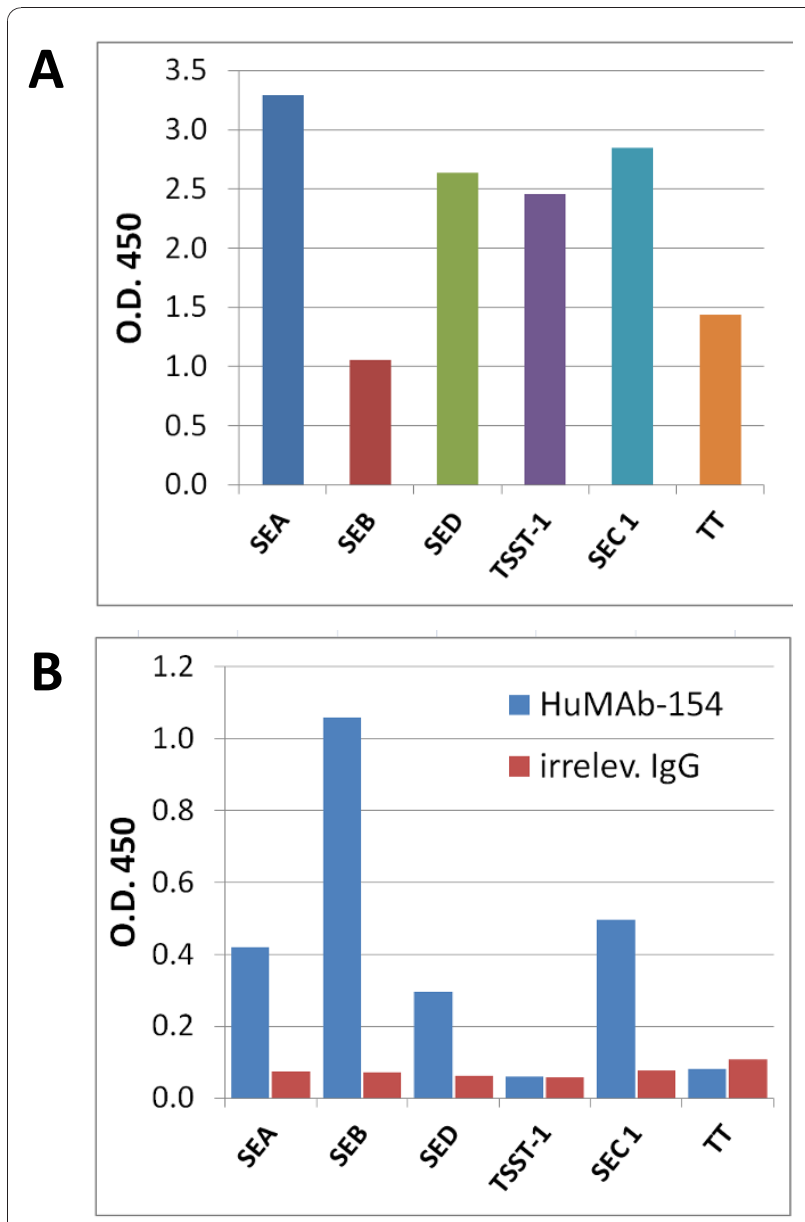

Figure 4 Cross-reactivity of HuMAb-154 to other bacterial toxins. A) Toxin-specific control Abs. B) HuMAb-154 and irrelevant hlgG reactivity against the panel of related toxins.

At this SEB dose level, most animals died within 24 hours post challenge and the remainder died within 48 hours. In contrast, $500 \mu \mathrm{g}$ of HuMAb-154 premixed with SEB conferred survival of mice at all SEB dose levels tested (14 days of observation period). HuMAb-154 prophylactic effect was dose-dependent: $100 \%$ survival at up to $10 \mu \mathrm{g}$ of SEB, while the percentage of surviving animals gradually decreased as the doses of SEB increased beyond $10 \mu \mathrm{g}$ of SEB (Figure 5B). Nonetheless, even at the highest challenge dose of $100 \mu \mathrm{g}, 40 \%$ survival of the animals treated with HuMAb-154 was observed.

\section{HuMAb-154 treatment following SEB challenge improves survival of mice}

Using the same Balb/C mouse model described above, additional studies were conducted to determine the therapeutic effects of HuMAb-154 administration following SEB challenge. In this model, $500 \mu \mathrm{g}$ of HuMAb154 was injected at different time points after SEB injection. In untreated animals, there was $100 \%$ mortality at 


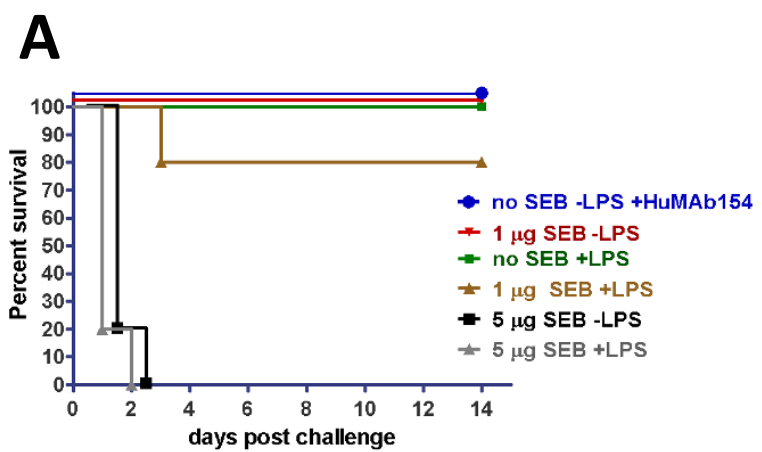

B

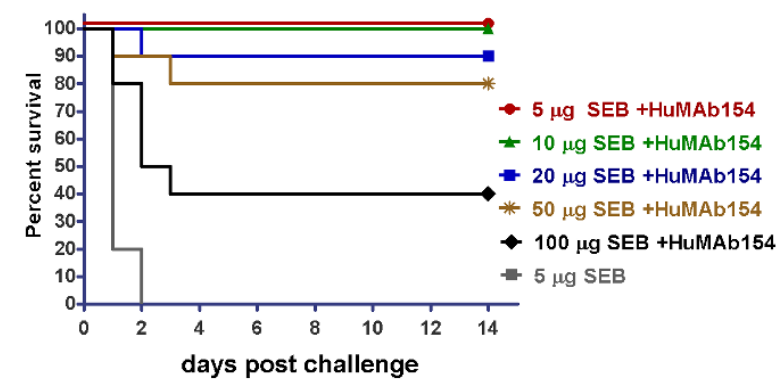

Figure 5 Prophylactic administration of HuMAb-154 protected mice exposed to lethal doses of SEB challenge. A) Kaplan-Meier survival chart demonstrates dose escalation of SEB in LPS prime model to find the minimal dose of SEB to reach 100\% mortality ( $n$ = 5). B) Effect of HuMAb-154 at a fixed dose $(500 \mu \mathrm{g})$ in the protection of LPS primed mice from an escalating SEB challenge. Each HuMAb-154 group contained an $n$ of 10 while the untreated contained an $n$ of 5 . Survival of each SEB challenge group that was administered HuMAb-154 was significant $(P<0.015)$ as compared to the $5 \mu \mathrm{g}$ SEB challenge group that was not administered HuMAb-154.

$10 \mu \mathrm{g}$ of SEB, whereby 14 of 15 animals in three independent experiments died within 24 hours after SEB challenge and the remaining mouse died within 48 hours (Figure 6). When HuMAb-154 was administered immediately after SEB challenge (0 hours), an average of $86 \%$ of the animals survived the challenge ( 26 of 30 mice in three independent experiments). When HuMAb-154 was administered 30 minutes or 1 hour after SEB challenge, $50 \%$ (15 of 30) or 13\% (4 of 30) of mice, respectively, survived the challenge while delaying death in the remaining animals. These results suggest that HuMAb-154 can potentially be administered after a lethal or incapacitating dose of SEB and still be able to prevent or delay death.

\section{Discussion}

Antibody technology has been proven as an effective means of blocking SEB-induced pathologies $[17,18,29,30]$. Furthermore, antibody therapeutics are a well understood segment of the current pharmaceutical industry with

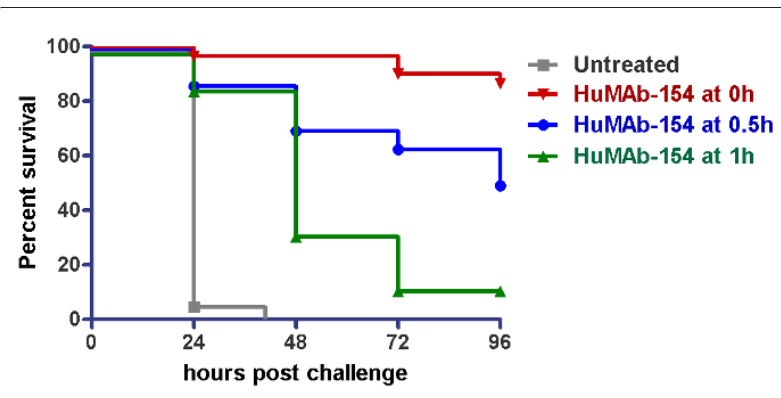

Figure 6 Kaplan-Meier survival chart showing HuMAb-154 treatment following SEB challenge improves survival of mice. Time to death was delayed in mice treated with HuMAb-154 shortly after SEB challenge. Mice were challenged with $10 \mu \mathrm{g}$ of SEB and HuMAb-154 was administered at time points following SEB challenge as indicated. Data are cumulative results of three studies ( $n=30$ for each group). Survival of each HuMAb-154 treatment group was significant $(P<0.0001)$ as compared to the untreated group.

many monoclonal candidates already on the market or in the pipeline for several disease indications, and represent a better option over small peptide-based approaches for neutralizing SEB due to their longer half-lives in sera, higher affinities, and reduced immunogenicity. Sources of antibodies usually include (a) animal plasma or serum (antisera); (b) human serum from immunized or convalescent individuals; (c) mammalian cells producing rodent monoclonal antibodies (hybridomas), rodent-human chimeras or humanized antibodies; or (d) mammalian cells producing fully human MAbs.

Animal antisera have been used since the early part of the 20th century to treat toxins like tetanus and diphtheria. The advantages of this approach include its low cost and effectiveness. Disadvantages include potential toxicity upon first and especially on second injection due to the foreign nature of the animal product, which may cause an immune response in humans (serum sickness). Hyperimmune human sera are widely used (e.g. varicella, hepatitis B, CMV and rabies) and are safe and effective. The challenges with such a strategy applied to the SEB case include i) the identification of a large number of human subjects with SEB-specific antibodies, ii) pathogen testing, pooling, storing and processing of the sera to make a safe drug product, and iii) the batch-to-batch variation in the product.

Rodent and rodent-human chimera MAbs can be produced in large scale, but since they retain a significant rodent (foreign) portion, they can have the same immunogenicity as animal antisera. Humanized MAbs retain $5-10 \%$ of rodent material. Thus, the immunogenicity of these molecules is reduced but some risks may remain. Because human MAbs do not contain any foreign sequences, they represent the first choice for safe drugs that can be reproducibly manufactured in large scale and indefinitely. 
To this goal, we have successfully generated human MAbs that are capable of neutralizing high doses of SEB both in vitro and in vivo. Our lead antibody HuMAb154 was selected for further characterization because of its high affinity and in vitro high potency and was tested in mouse models of SEB-induced lethality. HuMAb-154 could protect mice prophylactically from a challenge up to $100 \mu \mathrm{g}$ of SEB injected intraperitoneally, as well as therapeutically, conferring significant protection when administered 30 minutes after SEB challenge. Even though it lost most of its protective effect when administered one hour after SEB challenge, HuMAb-154 significantly delayed the time to death in some animals. It is known that the onset of the SEB-induced toxicity is very rapid and death occurs within 24 hours in most LPS-potentiated mice as reported in other studies [9]. In an LPS-independent mouse model of airway exposure (a route thought to be relevant for mass delivery of SEB in the human population), transgenic mice bearing the human leukocyte antigen-DQ8 died as late as 6 days after $15 \mu \mathrm{g}$ of aerosol SEB challenge [31]. This evidence further emphasizes the aggressive nature of the SEB toxicity observed in our Balb/C mouse model and indicates that the window of opportunity for therapeutic intervention in this model is very short.

The features of the toxicity induced by aerosolized SEB are not well understood due to the rarity of natural exposures in human. However, it is conceivable that non-human primate models better mimic the progression of the toxicity predicted in humans and may offer a wider window for therapeutic intervention. We will therefore explore these models to further test HuMAb154 efficacy in vivo for both prophylactic and therapeutic countermeasures of SEB exposure.

\section{Conclusions}

There are still no readily available therapeutics to counteract the effects of SEB intoxication, whether the exposure is a result of food poisoning or exposure to a weaponized (aerosol) form of SEB. To this end, we have generated fully human, high-affinity SEB-specific antibodies with potent biological activity towards SEB. This report details the characterization of these antibodies thus providing detailed information for continued study to move these antibodies forward as potential therapeutics.

\section{Acknowledgements}

This work was supported by NIH-NIAID Grant \# 5U01Al075399. We would also like to thank J. Donald Capra and Andy Duty for their critical comments.

\section{Author details}

${ }^{1}$ Morphotek Inc., 210 Welsh Pool Road, Exton, PA, USA. ${ }^{2}$ U.S. Army Medical Research Institute of Infectious Diseases, Fort Detrick, Frederick, MD, USA.

\section{Authors' contributions}

$\mathrm{BD}$ and $\mathrm{YZ}$ carried out the study planning and execution, coordination of mouse studies, statistical analysis and manuscript preparation. BK, JS and YYC sequenced Ig genes and cloned for recombinant expression. EA measured HuMAb affinities. HT purified HuMAbs. QC oversaw the HTS of hybridomas. MH cultured hybridoma cell lines. JB was responsible for HTS of hybridomas. ER oversaw the purification of HuMAbs. SB contributed scientific advisory. NCN and PMS oversaw the general planning, design and implementation of this project. LG participated in the study planning, coordination of mouse studies, manuscript preparation. All authors read and approved the final version of the manuscript.

\section{Competing interests}

The authors declare that they have no competing interests.

Received: 5 November 2010 Accepted: 21 December 2010

Published: 21 December 2010

\section{References}

1. Lowy FD: Staphylococcus aureus infections. N Engl J Med 1998, 339:520-532.

2. Holbrook KA, Klein RS, Hartel D, Elliott DA, Barsky TB, Rothschild LH, Lowy FD: Staphylococcus aureus nasal colonization in HIV-seropositive and HIV-seronegative drug users. J Acquir Immune Defic Syndr Hum Retrovirol 1997, 16:301-306.

3. Miller M, Cook HA, Furuya EY, Bhat $M$, Lee $M H$, Vavagiakis $P$, Visintainer $P$, Vasquez G, Larson E, Lowy FD: Staphylococcus aureus in the community: colonization versus infection. PLoS One 2009, 4:e6708.

4. Lina G, Bohach GA, Nair SP, Hiramatsu K, Jouvin-Marche E, Mariuzza R: Standard nomenclature for the superantigens expressed by Staphylococcus. J Infect Dis 2004, 189:2334-2336.

5. Ono HK, Omoe K, Imanishi K, Iwakabe Y, Hu DL, Kato H, Saito N, Nakane A, Uchiyama T, Shinagawa K: Identification and characterization of two novel staphylococcal enterotoxins, types S and T. Infect Immun 2008, 76:4999-5005.

6. Chiang YC, Liao WW, Fan CM, Pai WY, Chiou CS, Tsen HY: PCR detection of Staphylococcal enterotoxins (SEs) N, O, P, Q, R, U, and survey of SE types in Staphylococcus aureus isolates from food-poisoning cases in Taiwan. Int J Food Microbiol 2008, 121:66-73.

7. Mattix ME, Hunt RE, Wilhelmsen CL, Johnson AJ, Baze WB: Aerosolized staphylococcal enterotoxin B-induced pulmonary lesions in rhesus monkeys (Macaca mulatta). Toxicol Pathol 1995, 23:262-268.

8. Ulrich RG: Staphylococcal Enterotoxin B And Related Toxins. Medical aspects of chemical and biological warfare 2007, 311-322.

9. Boles JW, Pitt ML, LeClaire RD, Gibbs PH, Torres E, Dyas B, Ulrich RG, Bavari S: Generation of protective immunity by inactivated recombinant staphylococcal enterotoxin B vaccine in nonhuman primates and identification of correlates of immunity. Clin Immunol 2003, 108:51-59.

10. Woody MA, Krakauer T, Stiles BG: Staphylococcal enterotoxin B mutants (N23K and F44S): biological effects and vaccine potential in a mouse model. Vaccine 1997, 15:133-139.

11. Yang X, Buonpane RA, Moza B, Rahman AK, Wang N, Schlievert PM, McCormick JK, Sundberg EJ, Kranz DM: Neutralization of multiple staphylococcal superantigens by a single-chain protein consisting of affinity-matured, variable domain repeats. J Infect Dis 2008, 198:344-348.

12. Wang $\mathrm{S}$, Li Y, Xiong $\mathrm{H}$, Cao J: A broad-spectrum inhibitory peptide against staphylococcal enterotoxin superantigen SEA, SEB and SEC. Immunol Lett 2008, 121:167-172.

13. Arad G, Levy R, Hillman D, Kaempfer R: Superantigen antagonist protects against lethal shock and defines a new domain for T-cell activation. Nat Med 2000, 6:414-421.

14. Buonpane RA, Churchill HR, Moza B, Sundberg EJ, Peterson ML, Schlievert PM, Kranz DM: Neutralization of staphylococcal enterotoxin B by soluble, high-affinity receptor antagonists. Nat Med 2007, 13:725-729.

15. Hamad AR, Herman A, Marrack P, Kappler JW: Monoclonal antibodies defining functional sites on the toxin superantigen staphylococcal enterotoxin B. J Exp Med 1994, 180:615-621.

16. Pang LT, Kum WW, Chow AW: Inhibition of staphylococcal enterotoxin B-induced lymphocyte proliferation and tumor necrosis factor alpha secretion by MAb5, an anti-toxic shock syndrome toxin 1 monoclonal antibody. Infect Immun 2000, 68:3261-3268. 
17. LeClaire RD, Hunt RE, Bavari S: Protection against bacterial superantigen staphylococcal enterotoxin B by passive vaccination. Infect Immun 2002, 70:2278-2281

18. LeClaire RD, Bavari S: Human antibodies to bacterial superantigens and their ability to inhibit T-cell activation and lethality. Antimicrob Agents Chemother 2001, 45:460-463.

19. Tilahun ME, Rajagopalan G, Shah-Mahoney N, Lawlor RG, Tilahun AY, Xie C, Natarajan K, Margulies DH, Ratner DI, Osborne BA, et al: Potent neutralization of staphylococcal enterotoxin B by synergistic action of chimeric antibodies. Infect Immun 2010, 78:2801-2811.

20. Li J, Sai T, Berger M, Chao Q, Davidson D, Deshmukh G, Drozdowski B, Ebel W, Harley S, Henry M, et al: Human antibodies for immunotherapy development generated via a human B cell hybridoma technology. Proc Natl Acad Sci USA 2006, 103:3557-3562.

21. Grunow R, Jahn S, Porstmann T, Kiessig SS, Steinkellner H, Steindl F, Mattanovich D, Gurtler L, Deinhardt F, Katinger $H$, et al: The high efficiency, human B cell immortalizing heteromyeloma CB-F7. Production of human monoclonal antibodies to human immunodeficiency virus. J Immunol Methods 1988, 106:257-265.

22. Ulrich RG, Olson MA, Bavari S: Development of engineered vaccines effective against structurally related bacterial superantigens. Vaccine 1998, 16:1857-1864.

23. Dinges MM, Orwin PM, Schlievert PM: Exotoxins of Staphylococcus aureus. Clin Microbiol Rev 2000, 13:16-34, table.

24. Proft T, Fraser JD: Bacterial superantigens. Clin Exp Immunol 2003, 133:299-306.

25. Swaminathan S, Furey W, Pletcher J, Sax M: Crystal structure of staphylococcal enterotoxin B, a superantigen. Nature 1992, 359:801-806.

26. Sundstrom M, Abrahmsen L, Antonsson P, Mehindate K, Mourad W, Dohlsten M: The crystal structure of staphylococcal enterotoxin type $D$ reveals Zn2+-mediated homodimerization. EMBO J 1996, 15:6832-6840.

27. Schad EM, Zaitseva I, Zaitsev VN, Dohlsten M, Kalland T, Schlievert PM, Ohlendorf DH, Svensson LA: Crystal structure of the superantigen staphylococcal enterotoxin type A. EMBO J 1995, 14:3292-3301.

28. Bavari S, Ulrich RG, LeClaire RD: Cross-reactive antibodies prevent the lethal effects of Staphylococcus aureus superantigens. J Infect Dis 1999, 180:1365-1369

29. Nishi Jl, Kanekura S, Takei S, Kitajima I, Nakajima T, Wahid MR, Masuda K, Yoshinaga M, Maruyama I, Miyata K: B cell epitope mapping of the bacterial superantigen staphylococcal enterotoxin $B$ : the dominant epitope region recognized by intravenous IgG. J Immunol 1997, 158:247-254

30. Visvanathan K, Charles A, Bannan J, Pugach P, Kashfi K, Zabriskie JB: Inhibition of bacterial superantigens by peptides and antibodies. Infect Immun 2001, 69:875-884.

31. Roy CJ, Warfield KL, Welcher BC, Gonzales RF, Larsen T, Hanson J, David CS, Krakauer T, Bavari S: Human leukocyte antigen-DQ8 transgenic mice: a model to examine the toxicity of aerosolized staphylococcal enterotoxin B. Infect Immun 2005, 73:2452-2460.

doi:10.1186/1476-8518-8-9

Cite this article as: Drozdowski et al: Generation and characterization of high affinity human monoclonal antibodies that neutralize staphylococcal enterotoxin B. Journal of Immune Based Therapies and Vaccines 2010 8:9.

\section{Submit your next manuscript to BioMed Central and take full advantage of:}

- Convenient online submission

- Thorough peer review

- No space constraints or color figure charges

- Immediate publication on acceptance

- Inclusion in PubMed, CAS, Scopus and Google Scholar

- Research which is freely available for redistribution

Submit your manuscript at www.biomedcentral.com/submit
Biomed Central 